\title{
Two-Stage Martensitic Transformation in NiTi Alloys Caused by Stress Fields
}

\author{
H. Morawiec, J. Ilczuk, D. Stróż, T. Goryczka and D. Chrobak \\ University of Silesia, Institute of Physics and Chemistry of Metals, Bankowa 12, 40-007 Katowice, \\ Poland
}

\begin{abstract}
It has been proved that the two-stage martensitic transformation in the NiTi alloys preceded by the Rphase transition my be induced by: low temperature annealing of the deformed alloy, thermal cycling and precipitation caused by ageing. The TEM observations of samples with two stage transformation have shown that the dislocations are distributed inhomogeneously and form a small-angle subgrain boundaries. The GranatoLucke analysis of the internal friction peaks related to the two-stage transformation confirmed the difference in dislocation density released in both stages. Thus the two stage martensitic transformation is caused by the inhomogenity in the stress field which results from the dislocation configuration during the previous mentioned processes.
\end{abstract}

\section{INTRODUCTION}

It is well known that the NiTi alloys during cooling undergo a martensitic transformation: $\mathrm{B} 2 \rightarrow \mathrm{B}^{\prime} 9^{\prime}$. This sequence may be changed into $\mathrm{B} 2 \rightarrow \mathrm{R} \rightarrow \mathrm{B} 19^{\prime}$ by changing chemical composition and/or by thermomechanical treatment. The structure of the R-phase which precedes the $\mathrm{B} 19^{\prime}$ transition is described as a rhombohedral deformation of the parent B2-phase along the $<111>$ direction. The first studies on the effect of deformation and annealing on change of the martensitic transformation sequence were carried out by Todoroki and Tamura [1]. The change in transformation sequence effects not only the characteristic transformation temperatures but also the shape recovery [2-4].

Annealing of the deformed alloys below the recrystalization temperature caused appearance of two peaks on the cooling DSC curve [1,5-6] which was interpreted as a two-stage martensitic transformation. The splitting of the DSC and internal friction cooling peaks was also observed as a result of ageing process [7-10] and cycling of the martensitic transformation [11-12].

The mechanism causing the two-stage martensitic transformation is still an open question. In this paper we try to prove that this two-stage transition is related to the inhomogenity in stress field which results from dislocation configuration generated by the recovery process, ageing or cycling.

\section{EXPERIMENTAL PROCEDURE}

In order to exhibit the two-stage martensitic transformation caused by means of three different procedures, two different alloys were chosen.

The first procedure - deformation and annealing was carried out on an alloy containing $50.6 \mathrm{at} \% \mathrm{Ni}$ (alloy No.1) which after annealing in the range from 400 to $500^{\circ} \mathrm{C}$ did not show any presence of precipitates. For the two next procedures - ageing and cycling an alloy containing 51 at. $\% \mathrm{Ni}$ was used (alloy No.2).

Specimens of alloy No. 1 in a shape of strips about $0.7 \mathrm{~mm}$ thick were quenched from $800^{\circ} \mathrm{C}$ after annealing for 1 hour and then cold rolled by $2 \%, 3.5 \%, 5 \%$ and $10 \%$ reduction. The deformed samples were then annealed at various temperatures between 300 and $700^{\circ} \mathrm{C}$. Specimens of alloy No. 2 had the same shape as these of alloy No.1. The specimens were solution treated at $800^{\circ} \mathrm{C}$ and then aged at 400 , 500,600 and $700^{\circ} \mathrm{C}$ for 1 hour. The transformation behaviour and the characteristic temperatures were determined using the DSC method on a Perkin Elmer instrument. The X-ray studies of the reversible 
martensitic transformation were carried out using a self -constructed cooling-heating attachment at the INEL position sensitive detector and CoK $\alpha$ radiation. The internal friction and vibration frequency as a function of temperature were measured using an acoustic frequency relaxator. To determine the dislocation density for the internal friction peak related to the particular transformations, measurements of amplitude dependencies of the internal friction were carried out. The IF-amplitude dependencies were conducted isothermally for the transformation peaks and at temperature related to the parent phase at $T=293 \mathrm{~K}$.

The structure of the specimens was observed by transmission electron microscope JEM 200B operating at $200 \mathrm{kV}$. Thin foils for TEM were prepared by the jet polishing technique in a solution containing 20 vol. $\% \mathrm{HClO}_{4}$ in $\mathrm{CH}_{3} \mathrm{COOH}$.

\section{EXPERIMENTAL RESULTS AND DISCUSSION}

The two-stage martensitic transformation preceded by the R-phase transformation is shown on the DSC cooling curves on Fig.1. The curves were obtained for specimens quenched from different temperatures i.e. 850,700 and $600^{\circ} \mathrm{C}$, then deformed by $\varepsilon=10 \%$ and annealed at $500^{\circ} \mathrm{C} / 1 \mathrm{~h}$. The presence of the same peaks proves that the quenching temperature has no influence on the transformation sequences. Hence it is seen that the amount of the quenched-in vacancies does not play a significant role in the mechanism of transformation. The X-ray diffraction pattern taken at $-35^{\circ} \mathrm{C}$ (Fig, 2a) which relates to the temperature

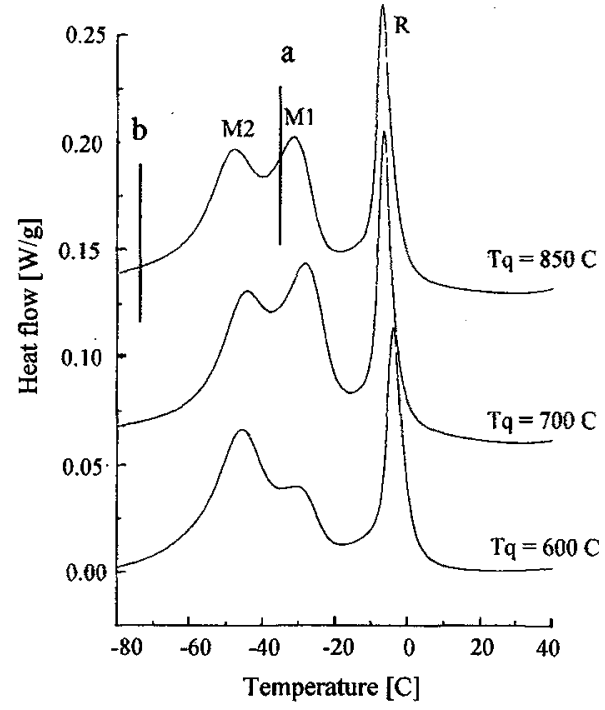

Figure 1: Effect of quenching temperature on two-stage martensitic transformation shown on DSC cooling curves.
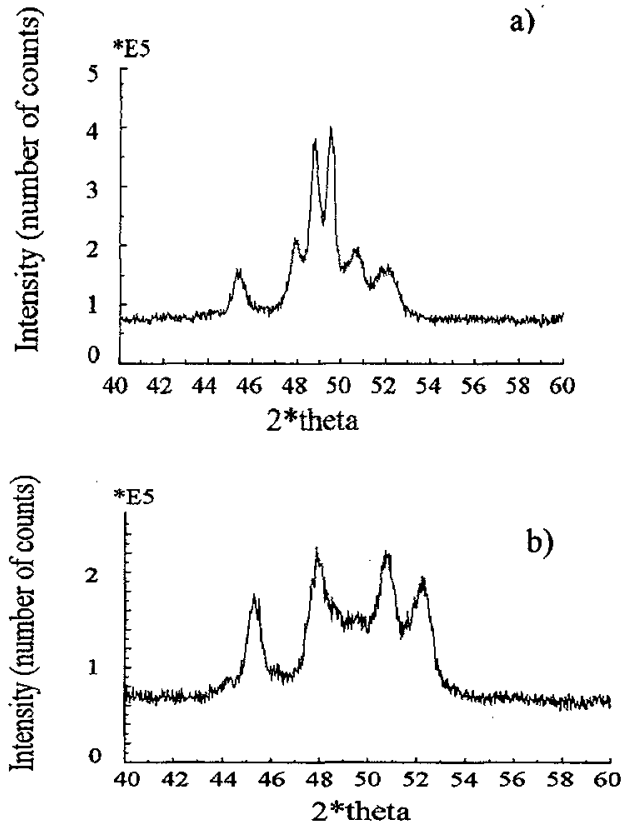

Figure 2: The diffraction pattern of a specimen annealed at $500^{\circ} \mathrm{C}$ previously deformed by $10 \%$

a) taken at $\mathrm{T}=-35^{\circ} \mathrm{C}$,

b) taken at $\mathrm{T}=-80^{\circ} \mathrm{C}$.

between the two peaks $\mathrm{M} 1$ and $\mathrm{M} 2$ shows presence of diffraction lines of the R-phase and the monoclinic B19' martensite and gives the evidence that the transformation has not finished. The next diffraction pattern taken at $-80^{\circ} \mathrm{C}$ relating to the temperature below the M2 peak shows only the lines from B19' martensite and proves the fact that the M2 peak on the DSC curves relates to the second stage of the martensitic transformation. Annealing of the deformed samples at temperatures causing recrystallization i.e. $\mathrm{T} \geq 600^{\circ} \mathrm{C} / 1 \mathrm{~h}$ change the DSC cooling curve which exhibits only one peak corresponding to B2 $\rightarrow \leftarrow$ B19' transformation. In order to explain the mechanism of the two-stage martensite transformation transmission microscopy studies were carried out to observe the change of dislocation structure. Dislocation density 
decreases with increase in annealing temperature of the deformed alloy [5]. Annealing at $500^{\circ} \mathrm{C}$ causes an advanced polygonization process forming regular network of dislocations and creating subgrains of smallangle boundaries shown on Fig.3a.

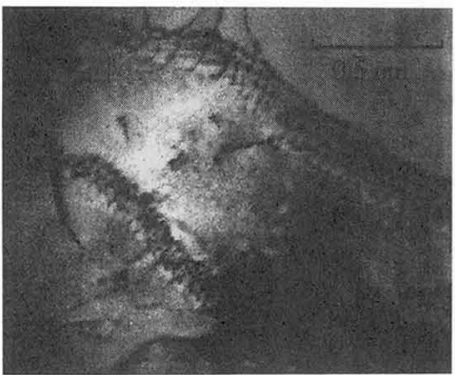

a)

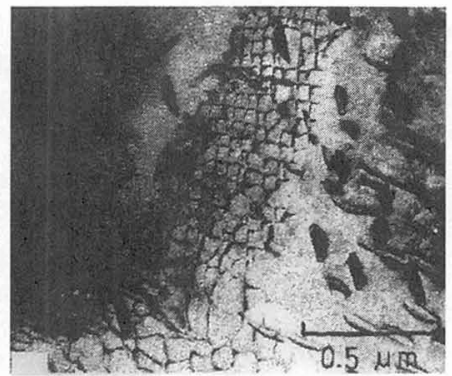

b)

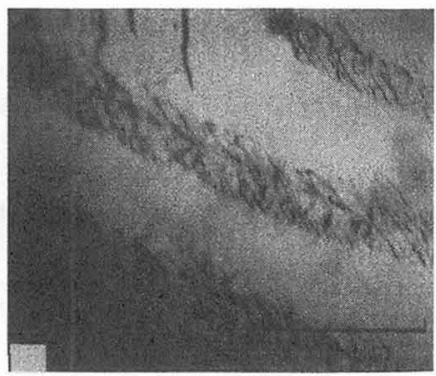

c)

Figure 3: Dislocation configuration of samples exhibiting two-stage martensitic transformation

a) deformation $\varepsilon=10 \%$ and annealed at $500^{\circ} \mathrm{C} / 1 \mathrm{~h}$ (alloy No1),

b) aged at $500^{\circ} \mathrm{C} / 1 \mathrm{~h}$ and cycled tree times (alloy No 2),

c) quenched and three times cycled (alloy No 2).

The formation of a small-angle boundary from a random distribution of dislocations may be understood in terms of the strain-field interaction. The stresses at the end of a dislocation wall segment attracts the surrounding edge dislocation which then become incorporated and results in the wall growth. These dislocation walls exist in parent phase and during martensitic transformation become an interface between parent and martensite - hindering the transformation.

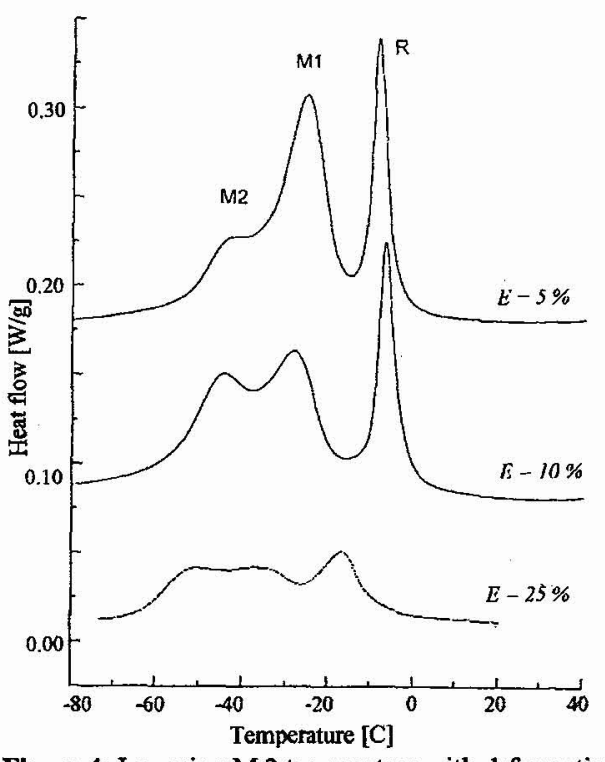

Figure 4: Lowering $\mathrm{M}_{\mathrm{s}} 2$ temperature with deformation degree before annealing at $500^{\circ} \mathrm{C} / 1 \mathrm{~h}$.

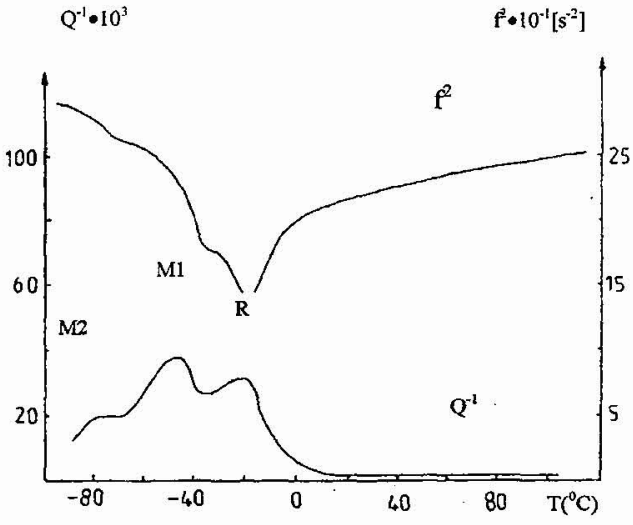

Figure 5: Plots of curves $Q^{-1}=f(T)$ for alloy No 1 deformed by $10 \%$ and annealed for 1 hour at $500^{\circ} \mathrm{C}$

This results in splitting the transformation into two regions differing in dislocation density. Additional support for this explanation may be the fact, that the M2 transformation which occurs in the higher dislocation density regions is shifted to lower temperatures at specimens with higher deformation before 
the annealing (Fig.4). To prove this suggestion further studies were carried out using the internal friction method (IF). The results confirmed the DSC studies. For the specimens which show the regular network of dislocations, one can distinguish three peaks on the IF cooling curve belonging to the R-phase transition and the two martensitic transformation peaks M1 and M2 - shown on Fig. 5 for a specimen annealed at $500^{\circ} \mathrm{C} / 1 \mathrm{~h}$ and previously deformed by $10 \%$. Fig. 6 presents the IF curves versus amplitude obtained isothermally and corresponding to the three peaks of transformation ( $R, M 1$ and $M 2)$ as well as to the parent phase $(P)$.The first region on the curves with the significant $Q^{-1}$ increase is related to the

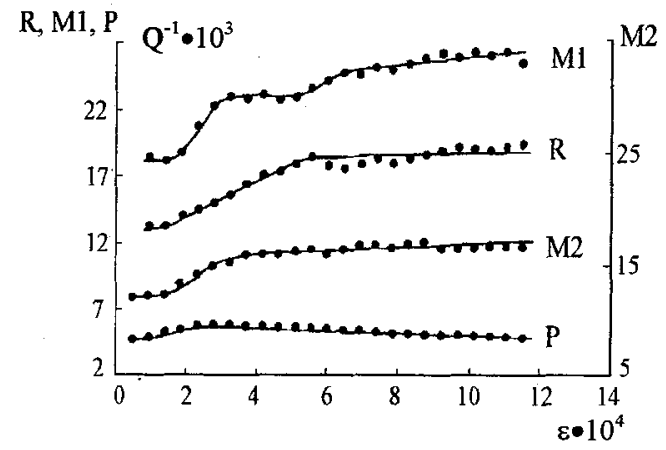

Figure 6: The IF amplitude dependence for alloy No 1 deformed by $10 \%$ and annealed at $500^{\circ} \mathrm{C}$ determined at peaks related to Fig. 5 as R $-250 \mathrm{~K}, \mathrm{M} 1-230 \mathrm{~K}, \mathrm{M} 2$ $204 \mathrm{~K}$ and for the parent phase $-\mathrm{P}$ at $293 \mathrm{~K}$

ratio ( 5.5) for peak M2 when compare with M1 (8) dislocation wall are more stable for the unpinning process. To field on the appearance of the two-stage martensitic transformation by means of precipitated particles of other phases, an alloy of higher nickel content was used (alloy No.2).

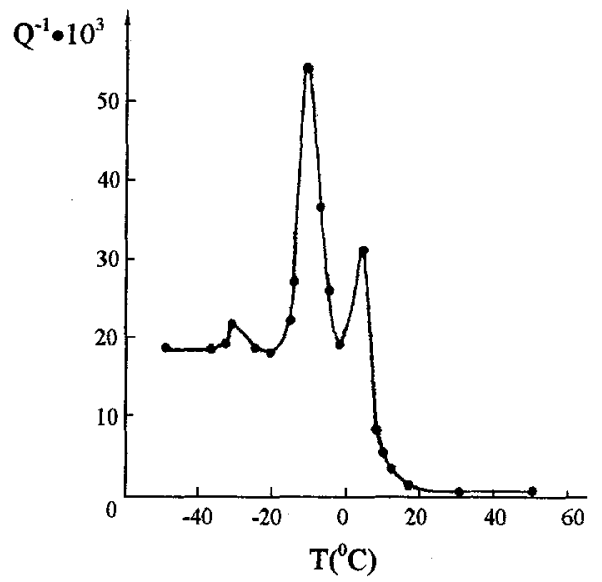

Figure 7:Internal friction cooling curve for the aged at $500^{\circ} \mathrm{C} / 1 \mathrm{~h}$ alloy No $_{2}$

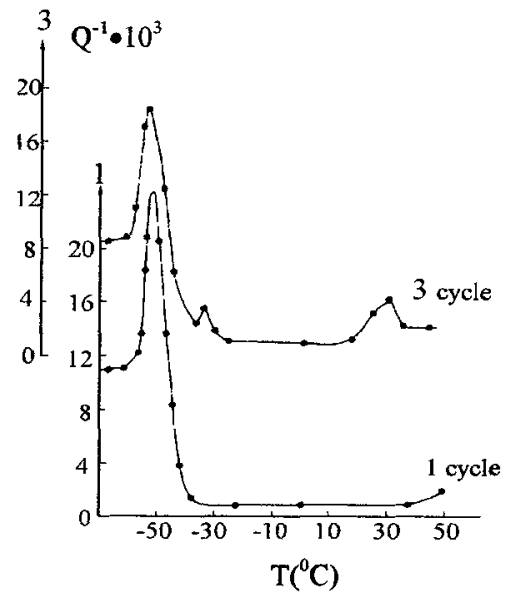

Figure 8: Internal friction cooling curve for the quenched alloy No 2 after the 1 and 4 cycles.

Samples after quenching exhibit only one peak on DSC and IF cooling curves relating to B2 $\rightarrow$ B19' transformation. The ageing of this alloy causes appearance of additional peaks like on Fig. 1 and Fig. 5 ( $R$, M1, M2). Fig. 7 shows the IF cooling curve for a specimen aged at $500^{\circ} \mathrm{C} / 1 \mathrm{~h}$ exhibiting the two-stage martensitic transformation. The semi- coherent precipitates show presence of dislocation loops. The twostage transformation in aged NiTi alloy was stated by Battaillard and Gotthard [7] as well as by Favier, Liu 
and McCormick [8] who claimed that the reason for that are the local stress field around precipitates. Fig. $3 \mathrm{~b}$ shows the small-angle boundaries for the aged specimen after three additional thermal cycles. Generation of dislocations by thermocycling is well known, Kajiwara and Kikuchi [19] demonstrated that repeating the transformation causes increase in the dislocation density. Fig. 8 shows the IF cooling curves for quenched from $700^{\circ} \mathrm{C}$ alloy No.2 after the first and third thermal cycle. This two-stage transformation could be seen even after two cycles of transformation. Fig.3c shows the dislocation configuration after three cycles, which also exhibit some tendency to form a small-angle dislocation boundaries.

Separation of the martensitic peak into two has recently been observed, [20] during incomplete thermal cycling. The authors concluded that the martensitic transformation was affected by strain fields occurring in the non-transformed parent phase and that the additional peak on the DSC curves results from locked-in transformation energy in the self accommodating martensite microstructure.

\section{CONCLUSION}

- Two-stage martensitic transformation in NiTi alloys is related to a distinguish splitting of this transformation peak on the DSC and IF cooling curve

- The two-stage martensitic transformation may be induced by the polygonization process, precipitation process or thermocycling

- All the processes are generating an inhomogeneous stress field caused by the dislocation configuration with a tendency to form a small-angle boundaries

- These dislocation boundaries exist in the parent phase and during martensitic transformation become an interface between parent and martensite - hindering the transformation.

\section{References}

[1] Todoroki T., Tamura H., Trans. Jap. Met. 28 (1983) 83.

[2] Sinfang Y., Yuing C., Ming Z., Long S., Guansen Y., Mat. Res. Soc Symp. Proc. 246 (1992) 283.

[3] Kao M.Y., Fariabi S., Thoma P.E., Ozkan H., Cartz L., Mat. Res. Soc. Symp. Proc 246 (1992) 225.

[4] Lin H.C., Wu S.K., Scripta Metall. Mater. 26 (1992) 59.

[5] Morawiec H., Stróż D., Chrobak D., J. de Physique IV 5 (1995) C2-205.

[6] Morawiec H., Stróż D., Goryczka T., Chrobak D., Scripta Mater. 35 (1996) 485.

[7] Bataillard L,, Gotthardt R., J. de Physique IV 5 (1995) C8-647.

[8] Favier D., Liu Y., McCormick P.G., Scripta Metall. Mater. 28 (1993) 669.

[9] Li J, Zhu J.S. Wang Y.N. phys. stat solidi. (a) 144 (1994)105.

[10] Stróż D., Kwarciak J., Morawiec H., J. Mater. Sci. 23 (1988) 4127.

[11] Stróż D., Bojarski Z., Ilczuk J., Lekston Z., Morawiec H., J. Mater. Sci. 26 (1991) 1741.

[12] Airoldi G., Riva G., Rivolta B., Proc. MRS Int. Meeting on Advanced Mater. 9 (1989) 105.

[13] Hasiguki R.R., Iwasaki K., J. Appl. Phys. 59 (1968) 2182.

[14] Zhu J.S., Schaller R., Benoit W., phys. stat. solidi (a) 108 (1988) 61.

[15] Koshimizu S., Mondino M., Benoit W., Proc. ECIFUAS-3 Manchester (1979) 269.

[16] Van Humbeeck J., Stoiber J., Delaey L., Gotthardt R., Z. Metallk. 86 (1995) 176.

[17] Granato A., Lucke K., J. Appl Phys. 27 (1956) 583, 789.

[18] Ilczuk J., Morawiec H., phys. stat. solidi (a) 97 (1986) 371.

[19] Kajiwara S., Kikuchi T., Acta Metall. 30 (1982) 589.

[20] Madangopol K., Banerjee S., Lele S., Acta Metall. Mater. 42 (1994) 1875. 